\title{
EVOLUTION OF CA PLAges OF THE CSSAR ACTIVE REgIONS
}

\author{
$\begin{array}{lll}\text { G. Godoli } & \text { and } & \text { B. Monsignori Fossi }\end{array}$ \\ (Astrophysical Observatory, \\ Catania, Italy)
(Astrophysical Observatory, Arcetri, Italy)

\section{A BST RACT}

For each plage of the CSSAR period the daily projected areas have been determined and plotted versus time. Also the correction for foreshortening has been taken into account.

Daily fluctuations, of the plage corrected areas, certainly greater than the errors, have been found. Also area fluctuations of shorter periods have been observed.

\section{Material Available}

During the IGY, IGC, CIG, IQSY campaigns, the World Data Center (WDC) C at the Arcetri Astrophysical Observatory collected and reduced material concerning Ca plages.

On the basis of the material collected for the IGY and IQSY campaigns a basic set was built as homogeneous as possible of at least one negative $\mathrm{K}_{2,3,2} \mathrm{Ca}$ heliogram per day with the diameter of the solar image of $63 \mathrm{~mm}$ (the size of the Arcetri spectroheliograms).

From this set the daily maps already published were deduced (Godoli, 1961a, $b$, $1962,1965,1966)$. The maps concerning the IGY period were also included in the IGY solar activity maps $D_{1}$ (Ellison, 1961).

Therefore for the CSSAR period the Arcetri WDC already had at its disposal at least one $\mathrm{K}_{2,3,2}$ heliogram per day. This material was sufficient for the study of the first CSSAR problem concerning the general evolution of Active Regions (AR).

A standardized file of at least one $K_{2,3,2}$ heliogram per day is now available at the Meudon Observatory for the period March 11 - December 1, 1965.

For the second problem concerning the birth and fast changes of AR during the first transit we have asked the observatories of Abastumani, Catania, Crimea, Fraunhofer, Ikomasan, Kodaikanal, Manila, McMath Hulbert, Meudon, Mount Wilson, Rome, Tokyo, Wendelstein, Zürich to send all the $\mathrm{K}_{2,3,2}$ material available for the periods:

$$
\begin{aligned}
& 11 \text { March - } 22 \text { March } 1 \text { July - } 4 \text { July } \\
& 14 \text { May - 26 May } 5 \text { July }-14 \text { July } \\
& 16 \text { May - 27 May 2 September-13 September }
\end{aligned}
$$

Kiepenheuer (ed.), Structure and Development of Solar Active Regions, 326-337. C I.A.U. 


$$
\begin{array}{rr}
1 \text { June }-9 \text { June } & 27 \text { September }-8 \text { October } \\
16 \text { June }-22 \text { June } & 1 \text { October }-6 \text { October }
\end{array}
$$

Every collaborating observatory has been asked to send to Arcetri negative prints or film (diameter of the solar image $63 \mathrm{~mm}$ ) or heliograms in the size and photographic presentation available.

\section{General Evolution}

For the study of the general evolution of each CSSAR Ca plage recognized in its successive transits in the visible hemisphere, we plotted versus time the daily projected areas $A P$ and corrected areas $A c$, taking into account the maximum deviations of the measurements.

The $A p$ areas determined on the maps drawn by contact on transparent paper directly from the heliograms and expressed in $10^{-4} E$ ( $E$ indicates the area of the solar hemisphere).

The drawing of the plage maps was the most difficult phase of the work: as is well known, the plages outlines are often disjointed and mixed with the chromospheric granulation; moreover, it is necessary to keep constant the examination of the brightness limit under which the phenomena are neglected. The estimation becomes complicated, moreover, by the non-linearity of the curve expressing the calibration of the photographic plate.

As far as the reproducibility of the plage maps is concerned, it was found that, if independent drawings were made by two different capable draftsmen using homogeneous heliograms, the differences of the areas within the plage outlines did not exceed $10 \%$. If the drawings were made by the same draftsman using inhomogeneous heliograms (made with different apparatus) the differences might be much higher. Therefore we choose for the basic set, as far as possible, heliograms of the same quality. We also tried to eliminate by interpolation some obvious differences among heliograms of consecutive days.

The projected areas $A p$ were transformed into corrected areas $A c$ according to the well-known formula

$$
A c=A p \sec h
$$

in which $h$ is the heliocentric angle of the plage.

We remember that the correction for foreshortening according to Equation (1) is based on the assumption that the effective plage layer is bidimensional and normal to the Sun's radius and that the values of corrected areas $A c$, for the same plage, do not depend on the distance from the centre of the disk. Since the plage area generally increases when the height on the photosphere of the effective layer increases, and therefore when $h$ increases (Anichini and Godoli, 1967), the second assumption is not fulfilled. This may be the reason why, as has been shown in a research recently carried 
out at Arcetri Observatory (Godoli and Monsignori Fossi, 1967a, b), the correction for foreshortening according to (1), although it is in fairly good agreement with the observations for 'great' plages with

$$
A c \geqslant 20 \times 10^{-4} E,
$$

it is no longer acceptable for 'small' plages with

$$
A c<20 \times 10^{-4} E \text {. }
$$

The difference between these two classes of plages can be ascribed to a probable different slope of the $A p(x)$ curve (with $x$ indicating the height on the photosphere).
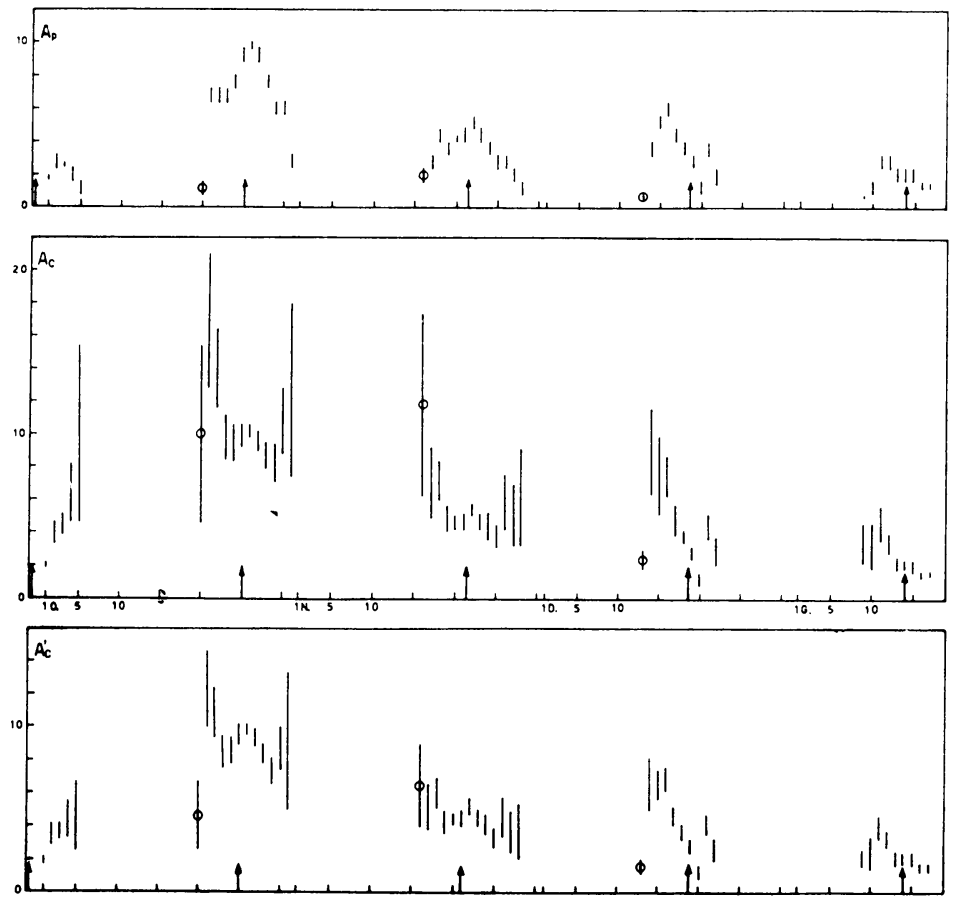

Fig. 1. Evolution of the small plage: 1964 Arcetri 18 (Godoli and Monsignori Fossi, 1967a).

In Figure 1 the evolution of a plage of the second class is shown. It is evident that correction (1) is not satisfactory. The $A^{\prime} c$ values, obtained by a statistical method, are more satisfactory (Godoli and Monsignori Fossi, 1967a, $b$ ). We notice that CSSAR plages are generally of the first class and therefore correction for foreshortening according to (1) was accepted. 


\section{Birth and Fast Changes of AR}

The $\mathrm{K}_{2,3,2}$ material especially requested for the second problem and received from cooperating observatories was as specified in Table 1. Only variations with time scale of $1^{\mathrm{h}}$ have been considered during the period listed above, in Section 1.A.

\section{Table 1}

\section{Material received}

Observatory

Abastumani
Arcetri
Freiburg
Kodaikanal
Locarno
Manila
McMath Hulbert
Meudon
Mount Wilson
Rome
Tokyo

\section{Material}

pos. copy film

neg. copy plate

orig. plate

pos. copy film

orig. plate

orig. film

pos. copy paper

pos. copy film

pos. copy film

pos. copy film

pos. copy paper
Diameter (mm)

20

63

45

19

68

83

64

84

14

63

When possible, at least one heliogram per 2 hours was reported to negative plates with one or two photographic inversions. The diameter of the solar image was reported at $63 \mathrm{~mm}$. This standardized file of heliograms is now available at the Meudon Observatory.

Actually, variations of the time scale of $1^{\text {h }}$ were pointed out from this file.

\section{The Evolution Curves}

In Figures 2-12 daily $A p$ and $A c$ values are plotted versus time for the $\mathrm{K}_{2,3,2} \mathrm{Ca}$ plages of the eleven AR selected for the CSSAR.

The maximum deviations of measurements are indicated. The circles indicate plages only partially visible on the disk. Arrows pointing from above indicate variations of the time scale of the hour. As already pointed out, these variations were studied only for the periods concerning the second problem. Arrows pointing from below indicate Central Meridian Passage.

The most interesting feature of these evolutive plottings are the daily variations of the areas clearly out of the limits of error.

Plage $1(30 \mathrm{~N})$ :

Born on disk near the East limb.

Daily fluctuations are present during the second transit. 


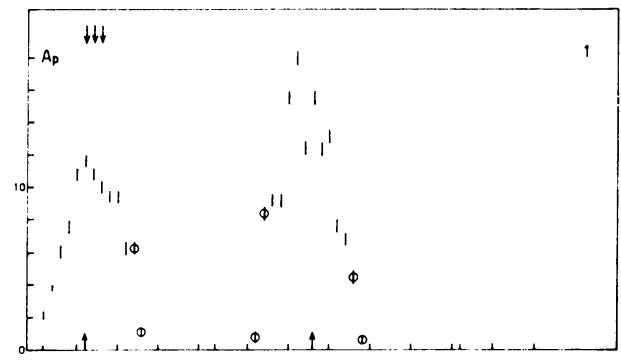

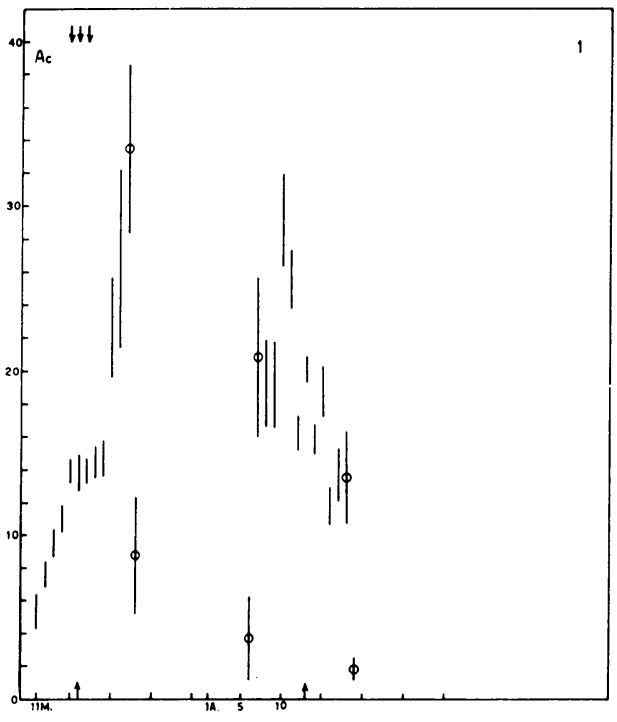

FIG. 2. CSSAR plage 1 .

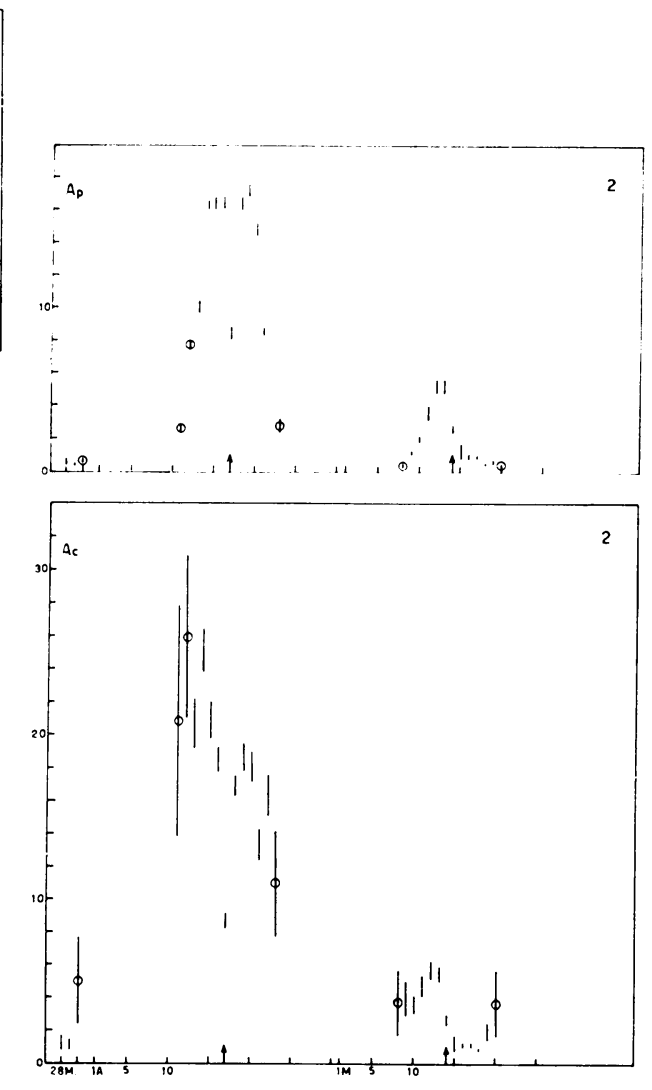

FIG. 3. CSSAR plage 2.

During the third transit the plage is still visible but under the compactness and brightness limit generally accepted.

Fast changes are present between

$$
\begin{array}{rllllll}
\text { March } & 16^{\mathrm{d}} & 09^{\mathrm{h}} & 04^{\mathrm{m}}-16^{\mathrm{d}} & 15^{\mathrm{h}} & 05^{\mathrm{m}} \\
16 & 15 & 05 & -16 & 23 & 33 \\
17 & 10 & 08 & -17 & 23 & 36 \\
17 & 23 & 36 & -18 & 00 & 54 \\
18 & 08 & 24 & -18 & 15 & 10 \\
18 & 15 & 10 & -18 & 23 & 32
\end{array} .
$$

Plage 2 ( $4 \mathrm{~N})$ :

Born on disk.

Daily fluctuations are present during the second transit. 


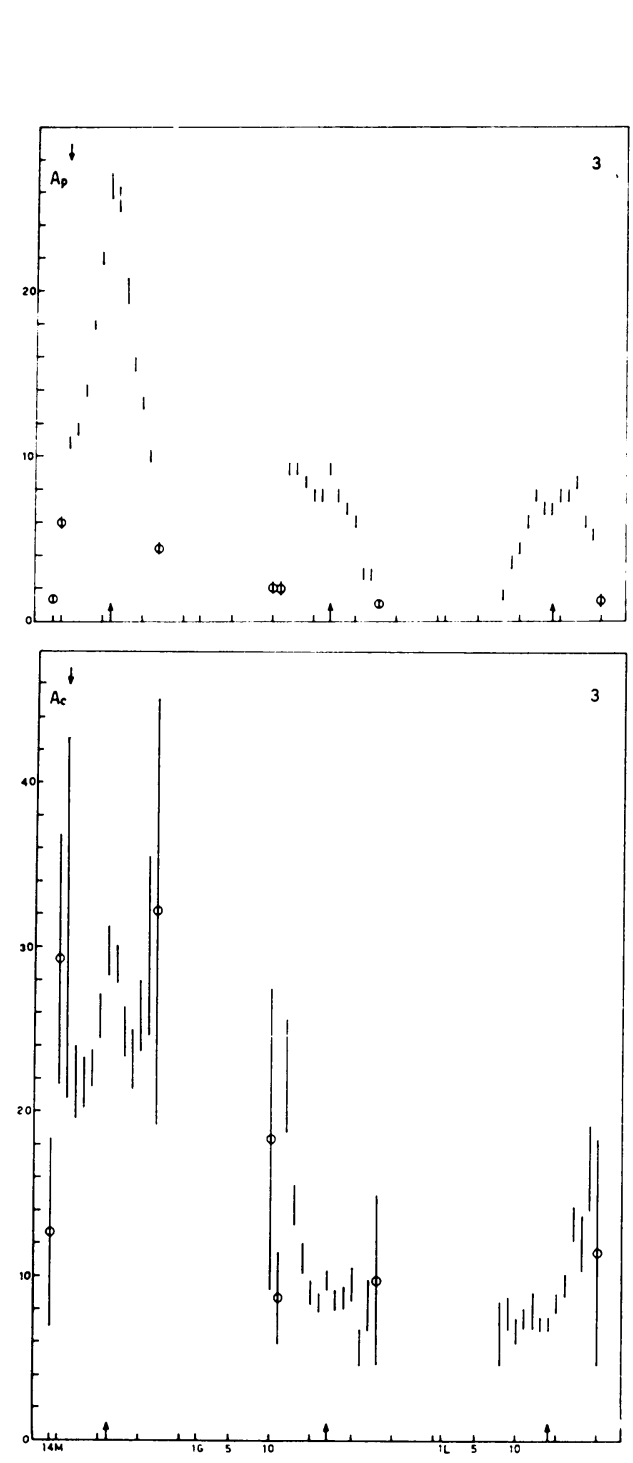

Fig. 4. CSSAR plage 3.
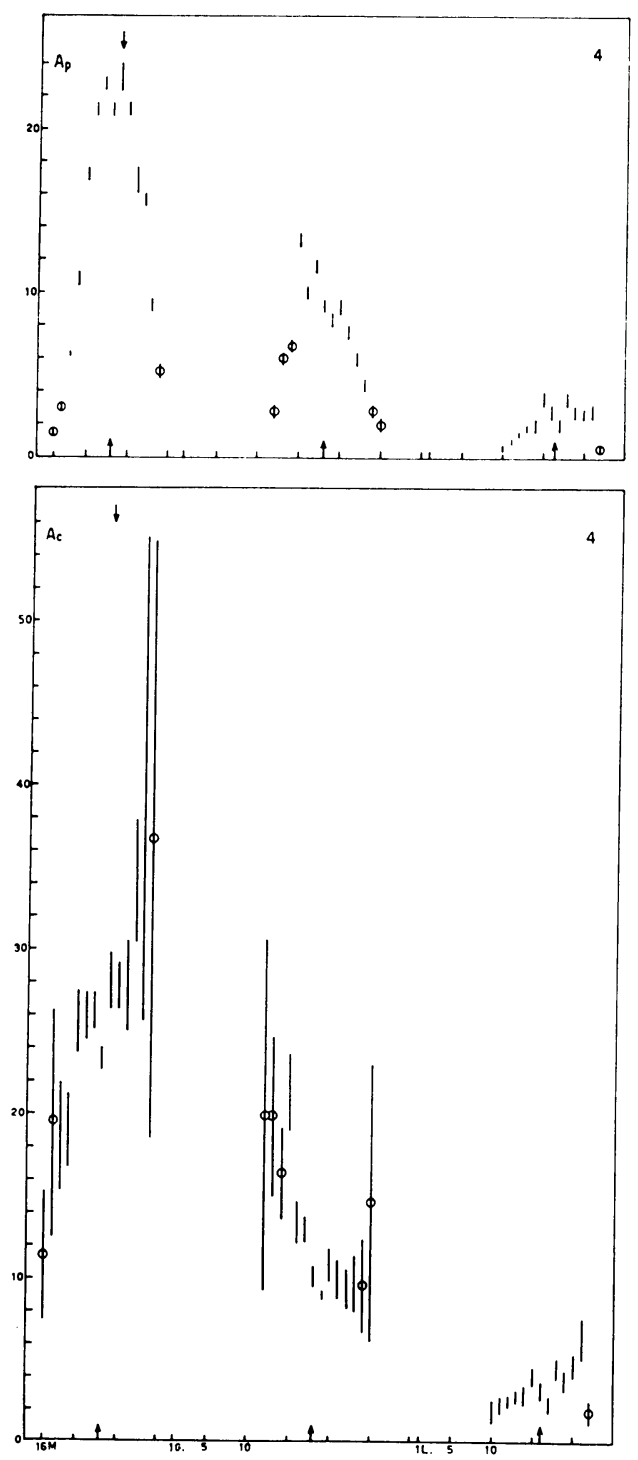

Fig. 5. CSSAR plage 4. 


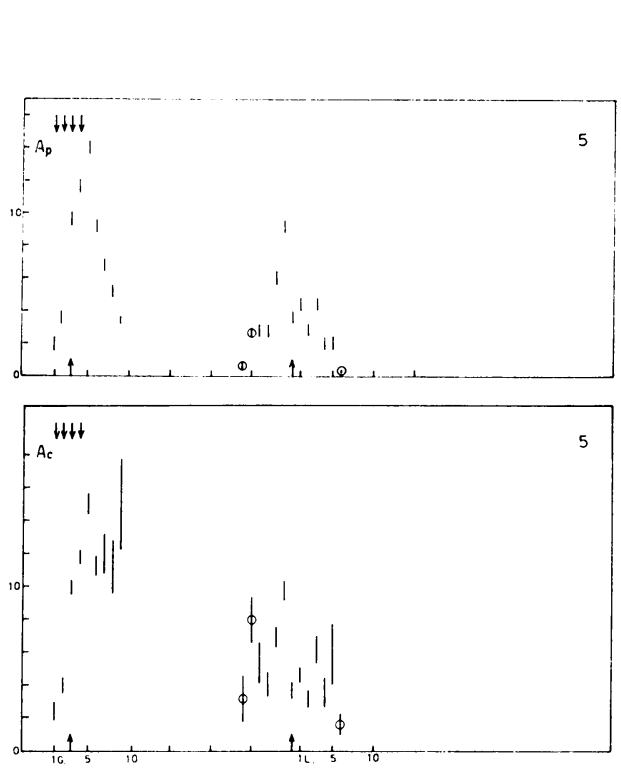

FIG. 6. CSSAR plage 5 .
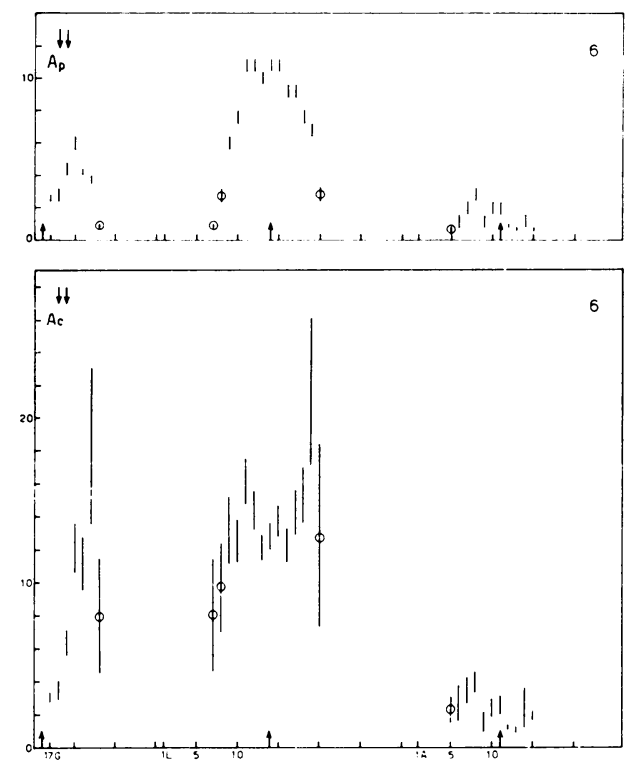

FIG. 7. CSSAR plage 6.

\section{Plage $3(23 \mathrm{~N})$ :}

This plage is very near to plage 4 .

During the second transit plages 3 and 4 interact, and it is very difficult to distinguish them from each other.

Daily fluctuations are present during the first transit.

Fast changes are present between

$$
\text { May } 16^{\mathrm{d}} 05^{\mathrm{h}} 28^{\mathrm{m}}-16^{\mathrm{d}} 13^{\mathrm{h}} 53^{\mathrm{m}}
$$

\section{Plage 4 ( $25 \mathrm{~N})$ :}

This plage is very near to plage 3 .

During the second transit plages 3 and 4 interact, and it is very difficult to distinguish them from each other.

Fast changes are present between

$$
\text { May } 23^{d} 10^{\mathrm{h}} 45^{\mathrm{m}}-24^{\mathrm{d}} 03^{\mathrm{h}} 36^{\mathrm{m}} \text {. }
$$

Plage $5(10 \mathrm{~S})$ :

Born on disk.

During the second transit the plage is not compact.

Fluctuations are present during the two transits.

Fast changes are present between 


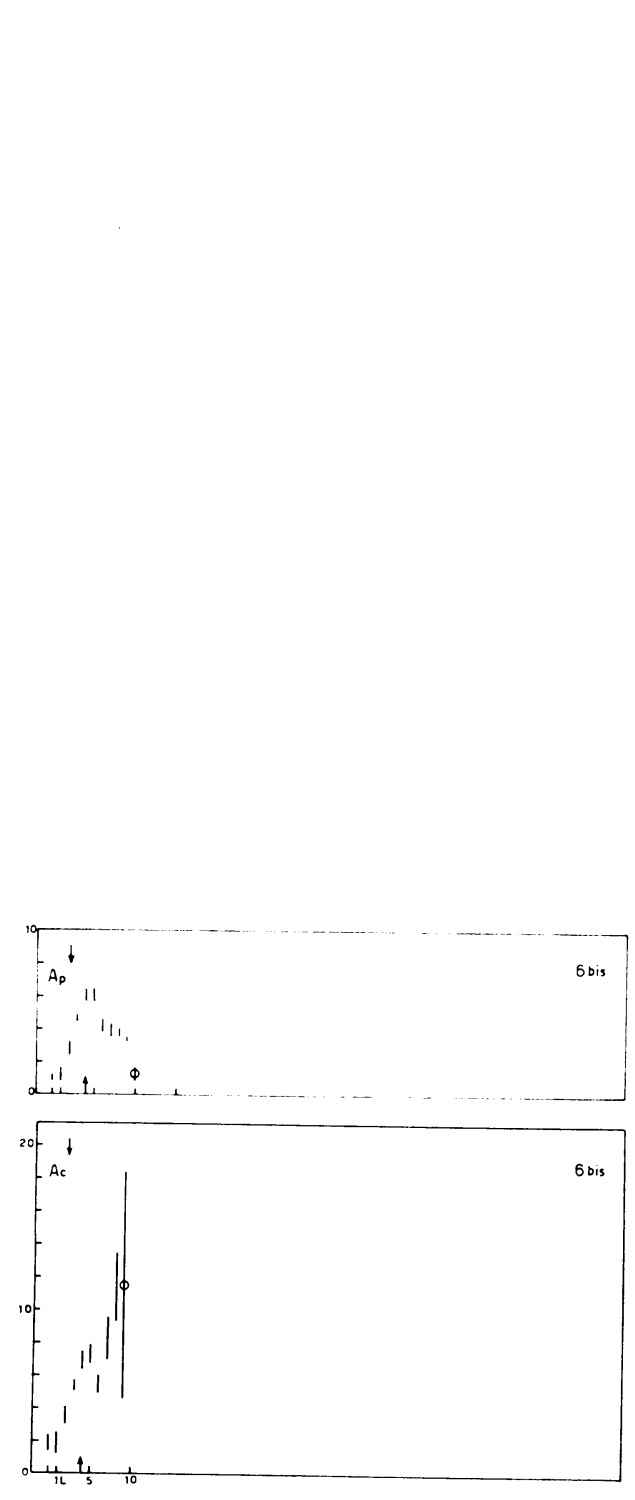

FIG. 8. CSSAR plage 6bis.
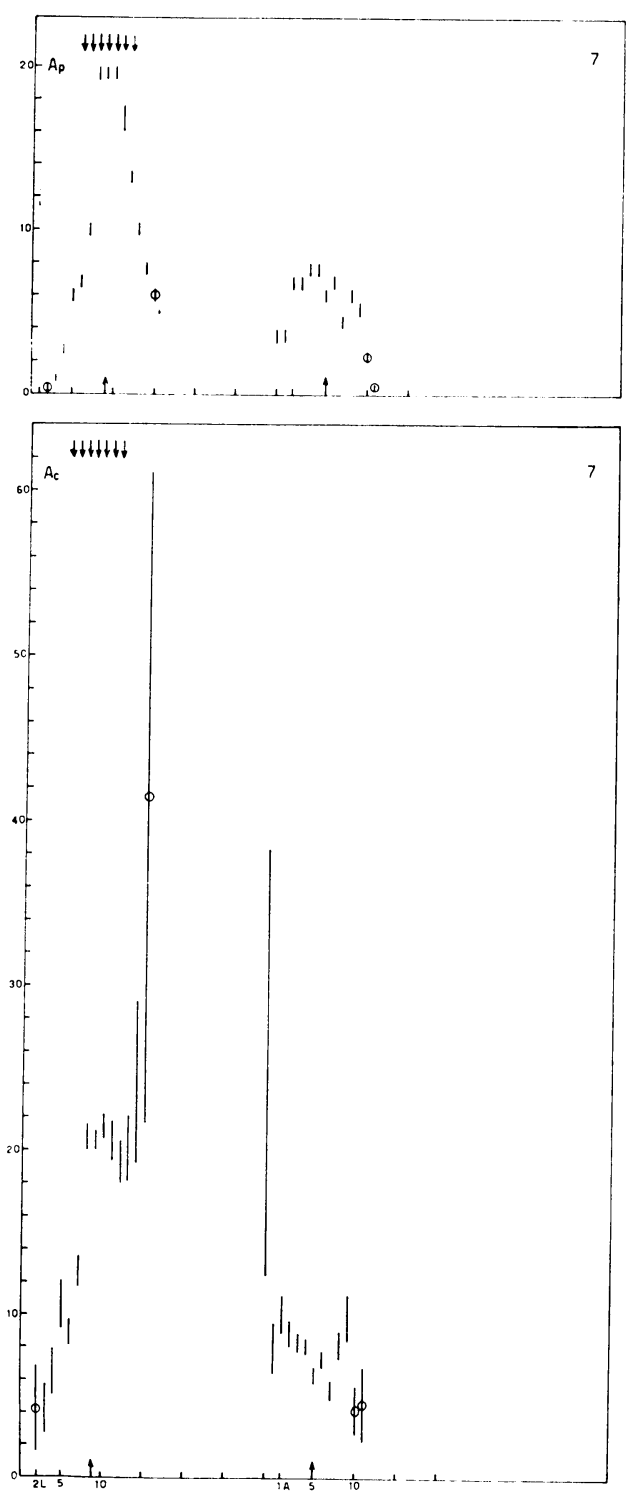

FIG. 9. CSSAR plage 7. 


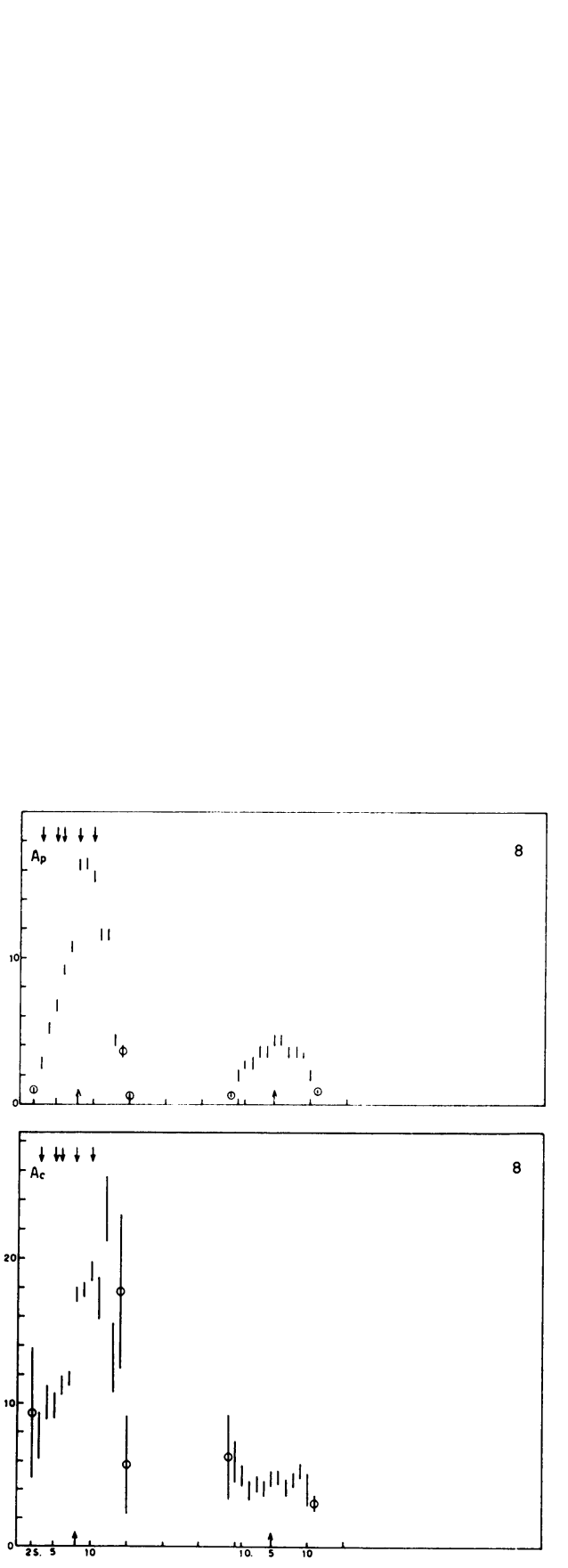

FIG. 10. CSSAR plage 8.
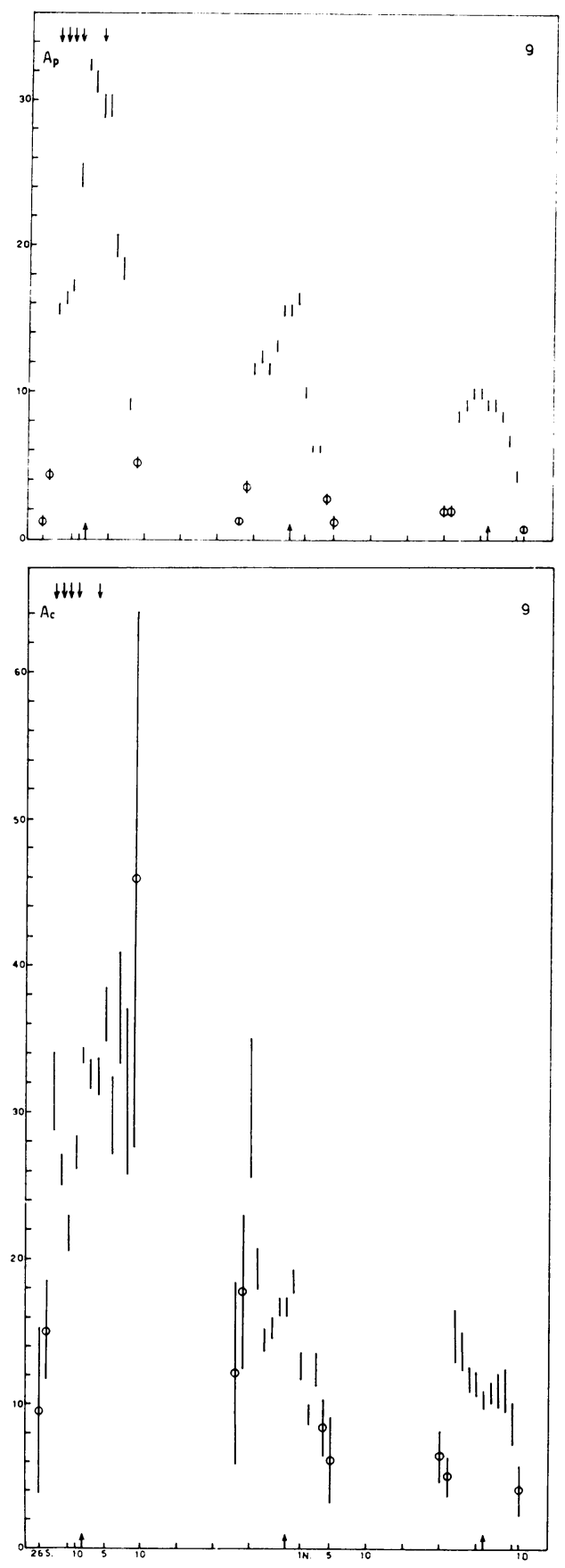

Fig. 11. CSSAR plage 9. 

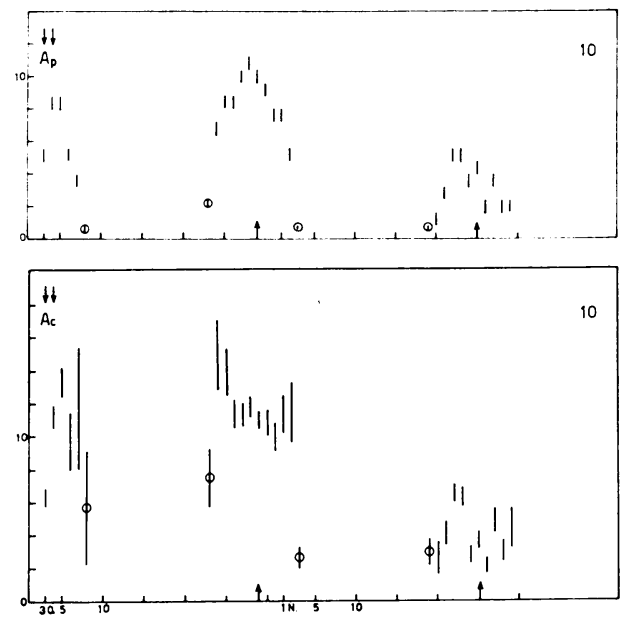

FIG. 12. CSSAR plage 10.

$$
\begin{array}{rllllll}
\text { June } & 1^{\mathrm{d}} & 13^{\mathrm{h}} & 20^{\mathrm{m}} & -1^{\mathrm{d}} & 16^{\mathrm{h}} & 15^{\mathrm{m}} \\
1 & 16 & 15 & -2 & 00 & 05 \\
2 & 09 & 02 & -2 & 14 & 41 \\
2 & 14 & 41 & -2 & 23 & 46 \\
2 & 23 & 46 & -3 & 02 & 22 \\
3 & 12 & 15 & -4 & 01 & 58
\end{array} .
$$

Plage 6 (28 S):

Born on disk.

During the third transit the region is disturbed by a new AR in the West side.

Fluctuations are present during the second transit.

Fast changes are present between

$$
\begin{array}{ccccccc}
\text { June } & 17^{\mathrm{d}} & 12^{\mathrm{h}} & 30^{\mathrm{m}} & -18^{\mathrm{d}} & 02^{\mathrm{h}} & 45^{\mathrm{m}} \\
18 & 05 & 43 & -18 & 09 & 17 \\
19 & 00 & 18 & -19 & 10 & 12 .
\end{array}
$$

Plage 6bis (32 N):

Born on disk.

Fast changes are present between

$$
\begin{array}{ccccccc}
\text { July } & 1^{\mathrm{d}} & 12^{\mathrm{h}} & 35^{\mathrm{m}} & -2^{\mathrm{d}} & 00^{\mathrm{h}} & 29^{\mathrm{m}} \\
2 & 03 & 09 & -2 & 08 & 27 \\
2 & 08 & 27 & -2 & 23 & 31
\end{array}
$$

Plage 7 (20 N):

During the first four days the plage is not compact. 
Fast changes are present between

$$
\begin{aligned}
& \text { July } 6^{\text {d }} 05^{\text {h }} 52^{\mathrm{m}}-6^{\mathrm{d}} 08^{\mathrm{h}} 44^{\mathrm{m}} \\
& \begin{array}{llllll}
6 & 23 & 59 & -7 & 00 & 45
\end{array} \\
& 70638-70826 \\
& \begin{array}{llllll}
8 & 01 & 16 & -81548
\end{array} \\
& 90241-90655
\end{aligned}
$$

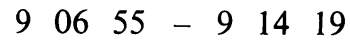

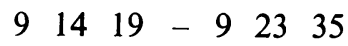

$$
\begin{aligned}
& \begin{array}{llllll}
9 & 23 & 35 & -10 & 04 & 52
\end{array} \\
& \begin{array}{llllll}
10 & 13 & 05 & -11 & 02 & 44
\end{array} \\
& \begin{array}{lllllll}
11 & 13 & 25 & -12 & 01 & 38
\end{array} \text {. }
\end{aligned}
$$

Plage $8(26 \mathrm{~N})$ :

Fast changes are present between

$$
\begin{aligned}
& \text { Sept. } 3^{\mathrm{d}} 02^{\mathrm{h}} 01^{\mathrm{m}}-3^{\mathrm{d}} 14^{\mathrm{h}} 00^{\mathrm{m}} \\
& 50040 \text { - } 50253 \\
& 50253-51635 \\
& 51635-60000 \\
& \begin{array}{l}
70845-72330 \\
10
\end{array} \\
& \begin{array}{llllll}
10 & 03 & 19 & -10 & 10 & 54
\end{array}
\end{aligned}
$$

Plage $9(20 \mathrm{~N})$ :

Fluctuations are present during the first two transits.

Fast changes are present between

$$
\begin{array}{|rrrrrrr}
\text { Sept. } & 28^{\mathrm{d}} & 01^{\mathrm{h}} & 25^{\mathrm{m}} & -28^{\mathrm{d}} & 16^{\mathrm{h}} & 50^{\mathrm{m}} \\
28 & 16 & 50 & -29 & 00 & 48 \\
29 & 06 & 13 & -29 & 23 & 31 \\
29 & 23 & 31 & -30 & 00 & 26 \\
& 30 & 09 & 39 & -30 & 23 & 28 \\
\text { Oct. } & 3 & 02 & 19 & -3 & 23 & 33
\end{array} .
$$

Plage 10 (18 S):

Born and died on disk.

Fast changes are present between

$$
\begin{array}{rllllll}
\text { Oct. } 3^{\mathrm{d}} & 02^{\mathrm{h}} & 19^{\mathrm{m}} & -3^{\mathrm{d}} & 07^{\mathrm{h}} & 59^{\mathrm{m}} \\
3 & 07 & 59 & -3 & 14 & 35 \\
3 & 14 & 35 & -3 & 23 & 33 \\
3 & 23 & 33 & -4 & 00 & 46 \\
4 & 00 & 46 & -4 & 08 & 44 \\
4 & 08 & 44 & -4 & 09 & 10
\end{array} .
$$




\section{References}

Anichini, M., Godoli, G. (1967) Mem. Soc. astr. ital., 38, 259.

Ellison, M.A. (ed.) (1961) IGY Solar Activity maps $\mathrm{D}_{1}$, Annals of the International Geophysical Year, 21, Pergamon Press, New York.

Godoli, G. (1961a) Osserv. Mem. Oss. astrofis. Arcetri, 73.

Godoli, G. (1961b) ibid., 75.

Godoli, G. (1962) ibid., 76.

Godoli, G. (1965) ibid., 82.

Godoli, G. (1966) ibid., 87.

Godoli, G., Monsignori Fossi, B.C. (1967a) Lincei, Mem., Serie VIII, 8, 85.

Godoli, G., Monsignori Fossi, B. C. (1967b) Solar Phys., 1, 148.

\section{DISCUSSION}

Rigutti: As Falciani, Righini Jr. and myself showed in Prague, if one estimates flare areas from contours judged by eye, one overestimates the areas of the limb flares with respect to the flare at the centre of the disk also for a factor of 1 or 2 orders of magnitude. If this were true also for plages, I wonder if your results could be affected by this uncertainty in fixing the areas.

Godoli: I do not think that the results found for flares near to the limb can be applied to plages: the flare contours must be generally estimated in a perturbed region, while the plage contours refer to the perturbed region as a whole. In Mem. Soc. astr. ital., 38, 75, 1967, you found that for plages near to the limb the area into contours estimated by eye is greater than the area into the isodense contours. I think that this fact can be explained, taking into account the instrumental limb darkening that is not taken into account with the isodense method you apply. Could this explanation also apply to your new flare measurements?

Rigutti: No, the measurements on flares to which I refer have been made in terms of the flare near the undisturbed chromosphere. So, any apparatus effect was the same for the flare region and for the background. 